\title{
A $21 \%$ conversion rate to total knee arthroplasty of a first-generation patellofemoral prosthesis at a mean follow-up of 9.7 years
}

\author{
Paul Hoogervorst ${ }^{1} \cdot$ Richard J. de Jong ${ }^{2,3}$. \\ Gerjon Hannink ${ }^{1} \cdot$ Albert van Kampen ${ }^{1}$
}

Received: 27 May 2015 / Accepted: 24 June 2015 /Published online: 1 August 2015

(C) The Author(s) 2015. This article is published with open access at Springerlink.com

\begin{abstract}
Purpose To evaluate the mid- to long-term results of the Richards' type II patellofemoral arthroplasty (PFA) in terms of functional scores, number and type of complications, patient satisfaction and survival.

Methods We retrospectively studied patients that received a Richards' type II PFA at our institution between 1998 and 2007. Patients with a functioning PFA at the time of this study were evaluated. Outcomes included survival rates with endpoint loss of prosthesis, number and type of complications, Knee Society Scores (KSS) and Visual Analogue Scale (VAS) for pain. In addition, patients were asked how surgery influenced their original symptoms.

Results Twenty-four patients (33 prostheses) were included. Follow-up ranged from 2.2 to 18.8 years with a mean of 9.7 years. Survival at 10 years was $73 \%(95 \%$ CI, 57$93 \%$ ). Median KSS score was 163 (range, 110-200). Median VAS Pain was 30 (range, 0-80) and VAS Satisfaction median was 90 (range, 50-100). Thirteen (62\%) PFAs were rated excellent, six $(28 \%)$ as good and two $(10 \%)$ as fair. Twelve $(36 \%)$ of the cases required further surgery within 4 years after implantation. Seven
\end{abstract}

Electronic supplementary material The online version of this article (doi:10.1007/s00264-015-2941-1) contains supplementary material, which is available to authorised users.

Richard J. de Jong

richardjdejong@gmail.com

1 Department of Orthopaedics, Radboud University Medical Centre, PO Box 9101, 6500HB Nijmegen, The Netherlands

2 Department of Orthopaedic Surgery, Leuven University Hospitals, Weligerveld 1, 3212 Pellenberg, Leuven, Belgium

3 Bodestraat 12-22, 3620 Lanaken, Belgium of these $(21 \%)$ were converted to TKA after a mean time of 5.5 years, five out of seven were converted because of ongoing tibiofemoral osteoarthritis (TFOA).

Conclusions We found a rate of $21 \%(7 / 33)$ conversion of the Richards' II PFA to TKA after a mean of 5.5 years; $71 \%(5 / 7)$ of cases were because of TFOA. We strongly advise not to use PFA if there is any sign of joint disease in other compartments than patellofemoral.

Keywords Patellofemoral arthroplasty · Primary arthroplasty $\cdot$ Cohort study $\cdot$ Patellofemoral

\section{Introduction}

Patellofemoral pain caused by isolated patellofemoral osteoarthritis (PFOA) is relatively common in general orthopaedic practice. It has been reported that $3.8-8 \%$ of knee pain due to cartilage degeneration is caused by isolated PFOA $[1,2]$. Patellofemoral arthroplasty (PFA) is a recognised treatment option for end stage isolated patellofemoral osteoarthritis (PFOA). The incidence in patients with knee pain in the population over 60 years old is approximately $15 \%$ [1]. A strikingly high percentage considering the percentage of PFA in all knee prostheses is less than $1 \%$ [3]. Apparently, despite the theoretical advantage of PFA over total knee arthroplasty (TKA) to treat only the involved compartment, TKA is more commonly used for PFOA. Past results do favour TKA above PFA, but newer implants seem to have improved PFA results. Recently it has been reported that first-generation PFAs have a higher likelihood of experiencing complications, re-operation, or revision surgery than second-generation PFAs. Mechanical complications were most commonly noted, followed by persistent pain and on-going (tibiofemoral) osteoarthritis [4]. Although we recognised these problems associated with 
first-generation PFAs, we were not convinced that the mentioned complications occurred in the same order and magnitude in our cohort of first-generation Richards' type II PFAs.

To analyse this assumption, we conducted this study to evaluate the mid- to long-term results of first-generation Richards' II PFAs performed in our centre in terms of functional scores, number and type of complications, patient satisfaction and survival. Survival was compared to the Orthopaedic Data Evaluation Panel (ODEP) benchmark of $90 \%$ survival rate at 10 years and with known data on the Richards' II PFA.

\section{Patients and methods}

We retrospectively studied patients that received a Richards' type II PFA (Smith \& Nephew Richards, Memphis, TN, USA) at our institution between 1998 and 2007. The Richards' II PFA has a particular constrained design with an inverted Vshaped cobalt chromium trochlea and a V-shaped polyethylene patella button. Data were retrieved from our institutions' databases. All patients were included consecutively. Our Institutional Review Board approved this study and all investigations were conducted in conformity with the ethical principles of research.

\section{Surgical technique}

Surgery was performed by a single surgeon. Antibiotic prophylaxis was administered in all cases. The joint was approached via a midline skin incision and medial parapatellar arthrotomy, after which all compartments were assessed. Sizing and placement was template assisted. Placement was carried out to respect patellofemoral alignment, prevent impingement of the anterior cruciate ligament distally and to prevent overstuffing of the patellofemoral compartment. Care was taken to reconstruct the position of the trochlear groove and to prevent either of the flanges to become proud. At the patellar side, patellar thickness was restored. Any part of the lateral facet that remained uncovered was removed to prevent impingement against the lateral femoral condyle or trochlear prosthesis. Stability (tilting, subluxation, lateral tightness), impingement and catching were tested over a full range of motion and addressed before the definitive components were cemented in place. Closure was done in a routine fashion. All patients were allowed partial weight-bearing with crutches from day 1 . Physiotherapy was continued after discharge if necessary. Since there were no contraindications, all patients routinely received antithrombotic prophylaxis for 6 weeks.

\section{Clinical follow-up and outcomes}

Patients with a functioning PFA at the time of this study were contacted and invited to our clinic for a clinical and radiological post-operative evaluation of the knee(s).

We computed two survival rates with different endpoints: loss of prosthesis (conversion to TKA or arthrodesis [AD]) and loss of integrity of the primary prosthesis (partial and full revision). Other outcomes were number and type of complications, Knee Society Scores (KSS) [5] and Visual Analogue Scale (VAS) for pain $(0=$ no pain, $100=$ worst pain imaginable $)$ and satisfaction $(0=$ least satisfied, $100=$ most satisfied). As a benchmark for survival, the ODEP criterion of $90 \%$ survival at 10 years was used. In addition, patients were asked how surgery influenced their original symptoms. Each patient was asked to score his/her own post-operative state into one of four categories: (1) excellent, asymptomatic after PFA, (2) good, improvement after PFA but not asymptomatic, (3) fair, no change after PFA, or (4) poor, worse after PFA.

Two recent radiographs of each PFA were evaluated for signs of loosening and malpositioning. One of the authors performed all radiographic evaluations and performed the clinical examinations.

\section{Statistical analysis}

Descriptive statistics were used to summarise the data. Dependent on distribution mean (SD) or median (range) were used. The Kaplan-Meier product limited estimator method was used for survival analysis. Patients that had died or were lost to follow-up were censored. Survival data are presented as percentage with $95 \%$ confidence interval (CI). All analyses were performed using SPSS 16.0 (SPSS IBM, Chicago, IL, USA).

\section{Results}

Twenty-four patients (33 prostheses) were included. Nine patients $(38 \%)$ were operated bilaterally. Demographic data showed a mean age at the time of surgery of 47.4 (32-81) years, 5 (21\%) men and 19 (79\%) women, a mean BMI of $28.2(19.6-42.85)$ and 16 left versus 17 right knees. Indications for PFA included idiopathic patellofemoral osteoarthritis (21 PFAs, $64 \%$ ), secondary patellofemoral osteoarthritis (patellofemoral dysplasia and/or malalignment without [sub]luxations) (10 PFAs, $30 \%$ ), secondary patellofemoral osteoarthritis with instability (1 PFA, $3 \%$ ) and posttraumatic osteoarthritis (1 PFA, $3 \%$ ).

For clinical follow-up, 21 of the 33 prosthesis were available; two patients (three PFAs) died due to PFA-unrelated 
causes, two patients (two PFAs) were not able to travel for reasons not related to the implant and a further seven PFAs were converted to TKA. Leaving a final total of 21 PFAs available and eligible for clinical follow-up. Two patients in this group had a functioning PFA on one side and a (converted) TKA on the other. The number of clinical patients followed-up was therefore 17, and not 15 as one might expect if only unilateral cases were present.

\section{Survival}

Survival analysis of the 33 PFAs (24 patients) with loss of the prosthesis (conversion to TKA or AD) as endpoint yielded a $73 \%$ survival rate at 10 years (95\% CI, 57-93\%) (Fig. 1). Survival rate when loss of integrity of the primary prosthesis was defined as endpoint (partial and full revision) was $71 \%$ at 10 years (95\% CI, 55-91\%) (Fig. 2).

\section{Clinical follow-up}

Median follow-up was 6.1 years and ranged from 2.2 to 18.8 years. The median KSS score was 163 (range, 110200), VAS Pain 30 (range, 0-80) and VAS Satisfaction 90 (range, 50-100). Thirteen PFAs (62\%) were rated as excellent, six (28\%) as good and two (10\%) as fair. All radiographs at the time of the evaluation showed adequate positioning of the PFA without any signs of loosening of the patellar or femoral component.

Fig. 1 Survival rate according to loss of the prosthesis (due to conversion to TKA or AD)

\section{Complications and re-operations}

Twelve of the original 33 (36\%) PFAs had additional surgery (Table 1). The indications for additional surgery varied. In five of the 12 cases ( $15 \%$ of all cases) ongoing tibiofemoral osteoarthritis (TFOA) was the main indication. Infection $(n=1$, $3 \%)$, pain and/or stiffness $(n=3,9 \%)$ and instability $(n=3$, $9 \%$ ) were the other indications. Seven PFAs were converted to TKA after a mean time of 5.5 years (2.7-7.2 years), five out of seven $(71 \%)$ because of TFOA.

In 28 surgical sessions, 31 additional procedures were performed. Most of these procedures were sequential. The median time to the first post-operative procedure was 4 years and 4 months (range, 10 days to 11 years).

Some individual cases contributed significantly to the number of procedures as is shown in Table 1. Case numbers 5, 6 and $11 \mathrm{R}$ contributed 13 to the 31 (42\%) additional procedures. Procedures prior to PFA implantation were also common; 33 knees underwent a total of 44 procedures. In Fig. 3 we present a chronological series of axial radiographs of a troublesome case, which eventually was converted to TKA (see also Table 1, case 5).

\section{Discussion}

We reported the mid- to long-term results of Richards' II PFA placed in our centre between 1998 and 2007 in terms of survival, functional scores, number and type of complications and patient satisfaction. The survival with conversion to

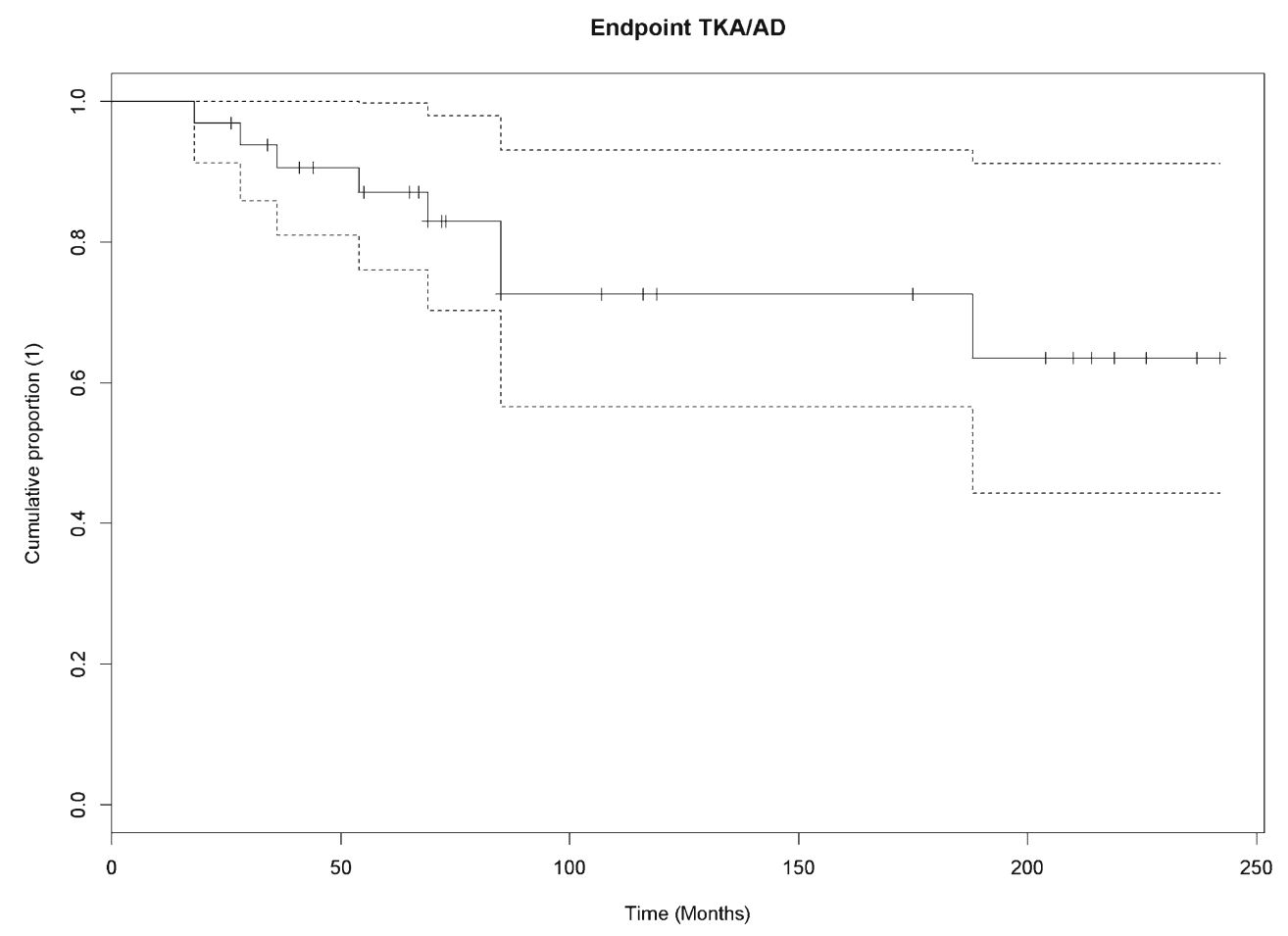


Fig. 2 Survival rate according to loss of integrity of the prosthesis
Endpoint TKA/AD/(Partial) Revision

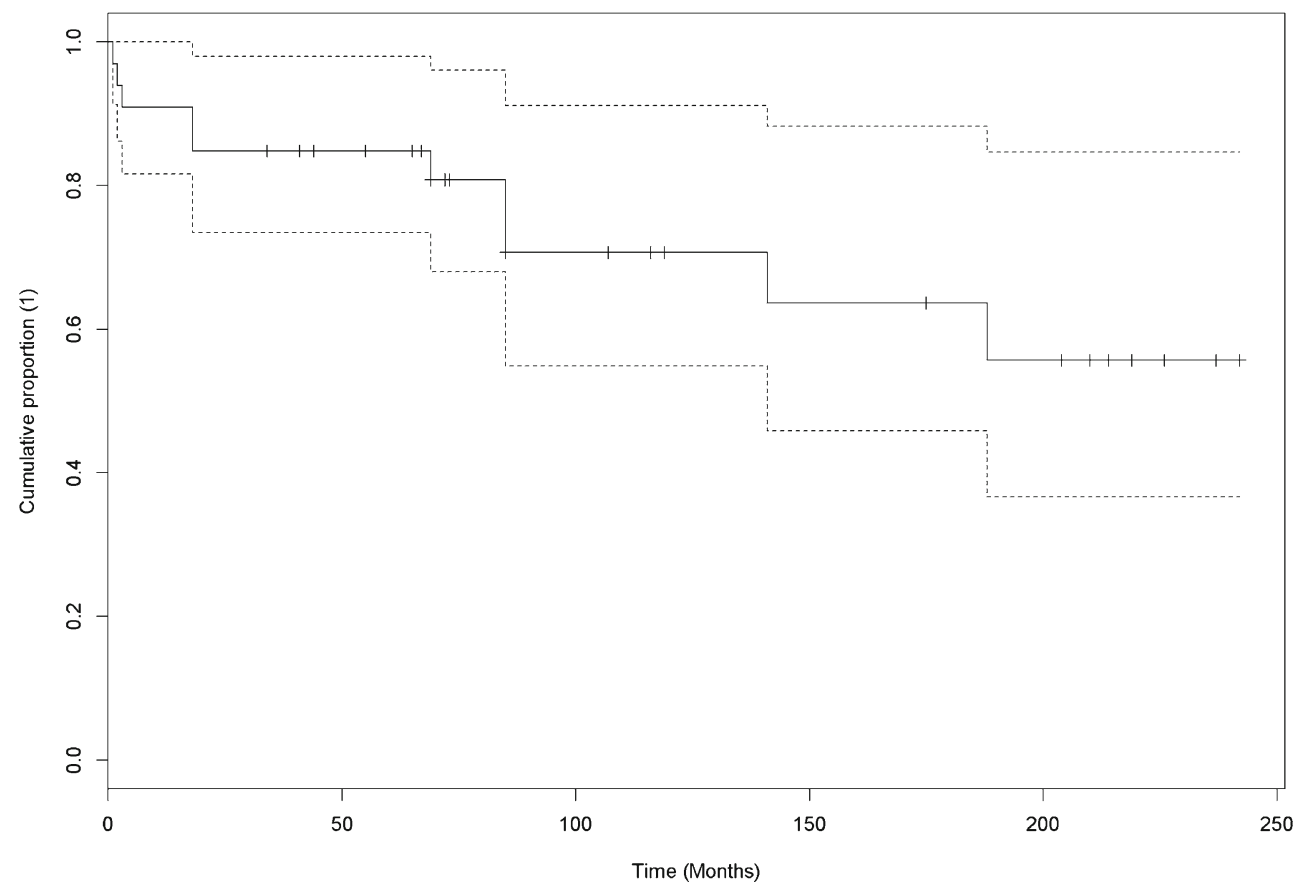

TKA as endpoint of $73 \%(95 \% \mathrm{CI}, 57-93 \%)$ at 10 years we found in our study is, taking the confidence interval in to consideration, comparable to published data on the Richards' II PFA, which varies from $75 \%$ (surgery for any reason, mean follow-up 10 [6-16] years) to approximately $84 \%$ (conversion to TKA, mean follow-up 13 [2-31] years) $[6,7]$. The ODEP benchmark of $90 \%$ survival at 10 years, widely accepted as a minimal requirement for total hip and knee arthroplasty, is not met, although $90 \%$ is still within the range of the confidence interval (57-93\%).

As mentioned in the introduction, the first generations of PFA experienced more complications than newer designs [8]. Our re-operation rate of $36 \%$ (12 out of 33) is higher than the $25 \%$ reported by Dy et al. [4]. In contrast, our patient satisfaction scores were good to excellent in $90 \%$, compared to $76-86 \%$ in the literature [3,9]. In the literature, mechanical complications were most commonly noted, followed by persistent pain and ongoing (tibiofemoral) osteoarthritis (TFOA) [4]. We saw the same type of complications but in a different order. Most common was TFOA ( $n=5,15 \%)$, followed by pain and/or stiffness $(n=3,9 \%)$, mechanical complications (instability) $(n=3$, $9 \%)$ and (deep) infection $(n=1,3 \%)$. We tried to deduct if these re-interventions could have been prevented. For the TFOA cases (Table 1: cases 1R, 4R, 1L, 9L and 11L) there does not seem to be a causal relationship with the primary indication or previous surgery. In these cases further surgery occurred 5.6-7.2 years after implantation. The infection case (Table 1: case 11R) was probably a low-grade infection from the start, becoming apparent at 1.5 years after implantation with no apparent link with patients preoperative history. However, this case was re-operated on multiple times because of tracking issues. The number of procedures are of course a risk factor for prosthetic joint infection (PJI). The pain and stiffness cases (Table 1: cases 6, 8 and 9R) all seem to have a more elaborate history that could influence the results of PFA, or any other type of surgery for that matter. But again there does not seem to be a direct causal link with patient history. Special consideration should be given to patellofemoral instability cases (Table 1 : cases $2 \mathrm{~L}, 3,5$ and also $11 \mathrm{R}$ ). The only case (Table 1: case 3 ) in which instability was the indication was also unstable after implantation of the device. Apparently the constrained design was not enough to solve these pre-existing patellofemoral dislocation issues. Possibly the re-intervention (a realignment) could have been prevented when a realignment procedure was done at or before PFA implantation. Our assumption that it is important to adequately treat instability before PFA is highlighted by cases $20,7 \mathrm{~L}$ and $7 \mathrm{R}$ (Table 1), in which a history of medialising tuberosity transfer osteotomies led to a good outcome after PFA. In contrast, a Maquet procedure does not seem to have the same effect. This is understandable because in this procedure there is only advancement of the tuberosity with no influence on stability.

The remaining instability cases (Table 1: cases $2 \mathrm{~L}, 5$ and 11R) had no previous history of instability. Either this was not apparent at the time of surgery or there are surgeon-related and/or implant-related factors that contributed to the post- 
Table 1 Summary of case characteristics and procedures

\begin{tabular}{|c|c|c|c|c|c|c|}
\hline Case & Indication for PFA & Previous surgery & $\begin{array}{l}\text { Indication for } \\
\text { further surgery }\end{array}$ & $\begin{array}{l}\text { Type of further } \\
\text { surgery }\end{array}$ & Time after PFA & $\begin{array}{l}\text { Satisfaction } \\
\text { rate }^{\mathrm{a}}\end{array}$ \\
\hline \multirow[t]{3}{*}{$1 \mathrm{R}$} & \multirow[t]{3}{*}{ Secondary PFOA } & Maquetplasty & MML & Arthroscopy & 5 years 5 months & \multirow[t]{3}{*}{ N/A } \\
\hline & & Arthroscopy $(\times 2)$ & MML & Arthroscopy & 6 years 5 months & \\
\hline & & Arthrotomy $(× 2)$ & TFOA & TKA & 7 years & \\
\hline $2 \mathrm{~L}$ & Idiopathic PFOA & Arthroscopy; PFCM & Subluxation & TTOT + VMO & 7 months & 1 \\
\hline 3 & $\begin{array}{l}\text { Patellofemoral dysplasia } \\
\text { with subluxation }\end{array}$ & - & Patella luxation & $\begin{array}{l}\text { Rev. patellar } \\
\text { component } \\
\text { + TTOT }\end{array}$ & 3 months & 2 \\
\hline $4 \mathrm{R}$ & Secondary PFOA & $\begin{array}{l}\text { Arthroscopic lateral } \\
\text { release }\end{array}$ & TFOA & TKA & 7 years 2 months & N/A \\
\hline \multirow[t]{4}{*}{5} & \multirow[t]{4}{*}{ Idiopathic PFOA } & \multirow[t]{4}{*}{ Arthroscopy; MML } & Subluxation & Rev. PFA & 3 months & \multirow[t]{4}{*}{ N/A } \\
\hline & & & Subluxation & $\begin{array}{l}\text { Rev. patellar } \\
\text { component }\end{array}$ & 9 months & \\
\hline & & & Subluxation & Arthrotomy & 3 years & \\
\hline & & & Subluxation & TKA & 3 years 2 months & \\
\hline \multirow[t]{6}{*}{6} & \multirow[t]{6}{*}{ Post-traumatic PFOA } & \multirow[t]{6}{*}{$\begin{array}{l}\text { Arthroscopy; PFCM, } \\
\text { post-op haemarthros }\end{array}$} & Stiffness & MUA & 10 days & \multirow[t]{6}{*}{ N/A } \\
\hline & & & Pain & Arthroscopy & 1 month & \\
\hline & & & Pain & Rev. PFA & 2 months & \\
\hline & & & Haemarthros & Arthrotomy & 2 months 12 days & \\
\hline & & & Persistent drainage & Arthrotomy & 2 months 17 days & \\
\hline & & & Persistent infection & Arthrodesis & 5 years & \\
\hline \multirow[t]{2}{*}{$1 \mathrm{~L}$} & \multirow[t]{2}{*}{ Secondary PFOA } & Maquetplasty & Medial pain & Arthroscopy & 5 years 2 months & \multirow[t]{2}{*}{ N/A } \\
\hline & & $\begin{array}{l}\text { Arthroscopic } \\
\text { perichondiumplasty }\end{array}$ & TFOA & TKA & 5 years 7 months & \\
\hline \multirow[t]{2}{*}{8} & \multirow[t]{2}{*}{ Secondary PFOA } & Maquetplasty & Stiffness & MUA & 16 days & \multirow[t]{2}{*}{2} \\
\hline & & Arthroscopy $(\times 2)$; PFCM & Stiffness & Arthroscopy & 7 years 4 months & \\
\hline \multirow[t]{3}{*}{$9 \mathrm{R}$} & \multirow[t]{3}{*}{ Secondary PFOA } & Maquetplasty & Pain & Arthroscopy & 11 years & \multirow[t]{3}{*}{1} \\
\hline & & \multirow[t]{2}{*}{$\begin{array}{l}\text { Arthroscopy }(\times 4) \text {; } \\
\text { PFCM, MML }\end{array}$} & Pain & $\begin{array}{l}\text { Rev. patellar } \\
\text { component }\end{array}$ & 11 years 9 months & \\
\hline & & & Pain & Arthroscopy & 12 years 9 months & \\
\hline 9L & Secondary PFOA & Maquetplasty & TFOA & TKA + TTOT & 5 years 8 months & N/A \\
\hline & & $\begin{array}{l}\text { Arthroscopy }(\times 3) \text {; } \\
\text { PFCM, MML }\end{array}$ & & & & \\
\hline $11 \mathrm{~L}$ & Idiopathic PFOA & - & TFOA & TKA & 7 years & N/A \\
\hline \multirow[t]{3}{*}{$11 \mathrm{R}$} & \multirow[t]{3}{*}{ Idiopathic PFOA } & \multirow[t]{3}{*}{-} & Loosening & $\begin{array}{l}\text { Rev. patellar } \\
\text { component }\end{array}$ & 1 year 6 months & \multirow[t]{3}{*}{ N/A } \\
\hline & & & Infection after revision & Extraction PFA & 2 years 5 months & \\
\hline & & & Infection after revision & TKA & 2 years 9 months & \\
\hline 12 & Idiopathic PFOA & Arthroscopy; PFCM & - & - & - & 2 \\
\hline 13 & Secondary PFOA & $\begin{array}{l}\text { Arthrotomy; total } \\
\text { synovectomy }\end{array}$ & - & - & - & 3 \\
\hline 14 & Idiopathic PFOA & Arthroscopy; MML & - & - & - & 2 \\
\hline 16 & Idiopathic PFOA & Arthroscopy; PFCM & - & - & - & 1 \\
\hline 17 & Idiopathic PFOA & Arthroscopy; PFCM & - & - & - & 1 \\
\hline 19 & Idiopathic PFOA & Arthroscopy; PFCM & - & - & - & 3 \\
\hline 20 & Secondary PFOA & $\begin{array}{l}\text { Trochleaosteotomy, } \\
\text { medialising TTOT }\end{array}$ & - & - & - & 2 \\
\hline 22 & Idiopathic PFOA & Arthroscopy; PFCM & - & - & - & 2 \\
\hline 24 & Idiopathic PFOA & Arthroscopy; PFCM & - & - & - & Lost to FU \\
\hline 10 & Idiopathic PFOA & MCL reconstruction & - & - & - & 1 \\
\hline $18 \mathrm{R}$ & Idiopathic PFOA & Arthroscopy; PFCM & - & - & - & 1 \\
\hline $2 \mathrm{R}$ & Idiopathic PFOA & Arthroscopy; PFCM & - & - & - & 1 \\
\hline
\end{tabular}


Table 1 (continued)

\begin{tabular}{|c|c|c|c|c|c|c|}
\hline Case & Indication for PFA & Previous surgery & $\begin{array}{l}\text { Indication for } \\
\text { further surgery }\end{array}$ & $\begin{array}{l}\text { Type of further } \\
\text { surgery }\end{array}$ & Time after PFA & $\begin{array}{l}\text { Satisfaction } \\
\text { rate }^{a^{a}}\end{array}$ \\
\hline $7 \mathrm{~L}$ & Secondary PFOA & $\begin{array}{l}\text { Maquetplasty } \\
\text { Medialising and } \\
\text { distalising TTOT } \\
\text { Arthroscopy; PFCM }\end{array}$ & - & - & - & 1 \\
\hline $7 \mathrm{R}$ & Secondary PFOA & $\begin{array}{l}\text { Medialising and } \\
\text { distalising TTOT } \\
\text { Arthroscopy; PFCM }\end{array}$ & - & - & - & 1 \\
\hline 15 & Idiopathic PFOA & - & - & - & - & Lost to FU \\
\hline $18 \mathrm{~L}$ & Idiopathic PFOA & - & - & - & - & 1 \\
\hline $21 \mathrm{~L}$ & Idiopathic PFOA & - & - & - & - & Lost to FU \\
\hline $21 \mathrm{R}$ & Idiopathic PFOA & - & - & - & - & Lost to FU \\
\hline $23 \mathrm{~L}$ & Idiopathic PFOA & - & - & - & - & 1 \\
\hline $23 R$ & Idiopathic PFOA & - & - & - & - & 1 \\
\hline $4 \mathrm{~L}$ & Idiopathic PFOA & - & - & - & - & 1 \\
\hline
\end{tabular}

$F U$ follow-up, $L$ left, $R$ right, $M M L$ medial meniscal lesion, $M U A$ manipulation under anaesthesia, $N / A$ not applicable, $P F A$ patellofemoral arthroplasty, $P F O A$ patellofemoral osteoarthritis, $P F C M$ patellofemoral chondromalacia, Rev. revision, Secondary PFOA patellofemoral osteoarthritis due to patellofemoral dysplasia and/or malalignment, TFOA tibiofemoral osteoarthritis, TKA total knee arthroplasty, TTOT tibial tuberosity osteotomy, VMO vastus medialis oblique reeving

${ }^{a}$ As rated by the patient at time of FU: 1. Excellent, asymptomatic after PFA; 2. Good, improvement after PFA but not asymptomatic; 3. Fair, no change after PFA; 4. Poor, worse after PFA

operative problems in these cases. This underlines the importance of proper surgical technique and possibly also reflects effects of low volume surgery. Cases 5 and 11R (Table 1) illustrate that once tracking problems exist it is not easy to resolve them by just revising a part of the complete prosthesis. As for possible implant-specific related issues, the high constrained design of the Richards' II easily leads to assumptions that it is less sensitive to medio-lateral instability. But you can also argue that in the pursuit of proper tracking there is less freedom of play compared to the current more mobile, less constraint designs. Hypothetically in this design, moderate malalignment could lead to polyethylene (over)loading of the (lateral) facet and trochlea shoulder leading to subsequent wear and pain because of strain on the soft tissues and particle disease. Observing the little to no polyethylene wear in conversion cases up to 12 years after primary implantation, overloading and wear did not seem to be a big issue in the Richards' II. Severe malalignment, however, could still lead to luxation, even in this design. As was shown in case 3 (Table 1). In the literature, more and more emphasis is being put on optimal implant positioning to achieve optimal tracking. Current designs use more sophisticated guiding instruments that mostly refer to the intramedullary femoral canal, anterior cortex, mechanical tibial axis, femoral epicondyles, direction of the native trochlea or a combination of these. Some authors remind us of the added value of navigation [10]. Most PFAs are based on TKA trochlea templates and anterior femoral cuts ("onlay") or sinking the trochlea shield into the native trochlea ("inlay"). These different options and supporting philosophies allow for different ways of implantation and positioning control [11], but there is no consensus on what the optimal method or position should be. In theory the amount of constraint in the Richards' II would make it less prone for implantation errors; but it seems that no matter which direction the patella is forced in, it will follow its own course. A number of cases (e.g. cases 5 and 11R) illustrate this point.

The V-shaped patellabutton is a concern for some authors because conversion to TKA means revising the patella as well [12]. To our knowledge, there is no discussion if the patella should be resurfaced or not in PFA, opposed to TKA $[13,14]$. In any case, in our experience the patellabutton does not cause problems in revision cases. It can be easily removed at the level of the bone cement-polyethylene interface. The remaining pegs can also be removed without effort. In all cases we were left with a good bone surface to receive a new patellar implant.

The ideal candidate for PFA, as proposed by Walker et al. [15], should be 50-60 years old, in our cohort the average age was 47.7 years, so not all our patients fit this profile. Also, there where disproportionally more women $(79 \%)$ than men (21\%), over-representing women.

A common re-operation was conversion to TKA because of ongoing tibiofemoral osteoarthritis in the medial or lateral compartment [4]. Seven of the 33 (21\%) cases were converted to TKA at an average time of 5.5 years after implantation; five of which were because of TFOA. The number of conversions would probably be lower if we were able 
Fig. 3 a-e A chronological series of axial radiographs of case 5
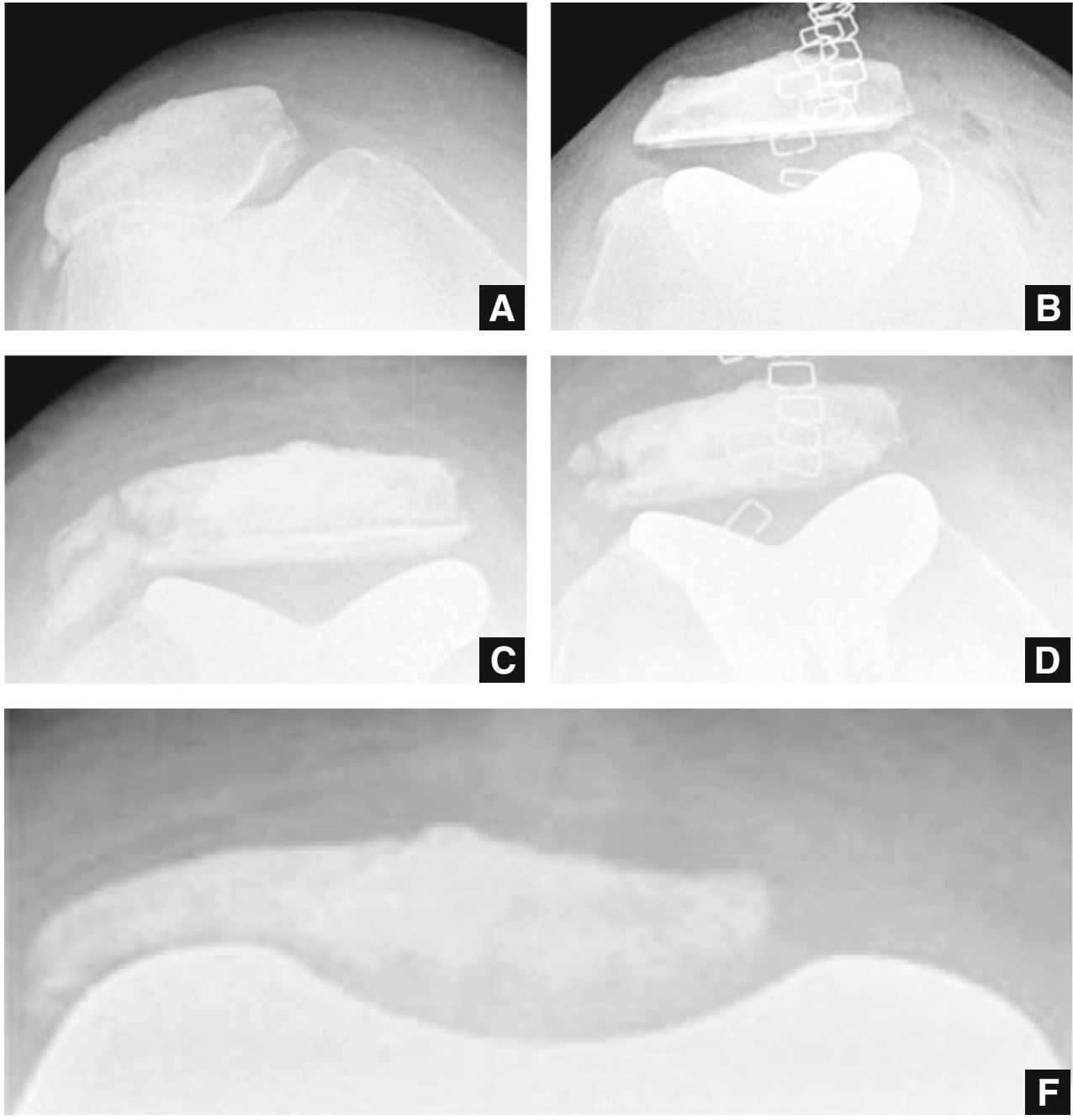

to predict which patients develop ongoing osteoarthritis. Presumably, in these patients signs of disease in other compartments were present when the indication for PFA was made, although not visible on X-rays. Pain in other areas of the knee than anterior is highly suggestive and should be investigated. Subclinical osteoarthritis can become apparent on magnetic resonance imaging (MRI), bone scintigraphy, single-photon emission computed tomography (SPECT) or arthroscopy [16-18], which can help to establish a correct diagnosis. In any case, we highly discourage using PFA in patients who show any symptoms of disease in other compartments than patellofemoral.

Patient selection, proper surgical technique, implant design and positioning, as well as surgical volume, probably all played a role in achieving the high operation rate in this cohort.

Some potential limitations of the study have to be discussed. First, although comparable to other studies, the study sample is relatively small [4]. Second, we have a relatively large number of bilateral cases (18 out of 33; $55 \%$ ). Both the small sample and the large percentage of bilateral cases may interfere with the survival analyses $[19,12,20$, 21]. Finally we did not use a PF specific questionnaire as in other PF related studies [14]. Strength of this study is that it is a single surgeon series.

In conclusion we found a 10-year survival of the Richards' II PFA of $73 \%$ (95\% CI, 57-93\%), which is comparable to known data but does not seem to meet the ODEP criterion of $90 \%$ survival at 10 years. Although re-operation rates are slightly higher than those published by other groups so are the satisfaction rates. We consider our results comparable to those reported in literature. According to current standards, implantation of this particular design should only be allowed in a controlled study environment. For this type of prosthesis, but we believe this can be extrapolated to current PFA designs, patient selection, proper surgical technique, implant design and positioning are crucial to optimise outcome. Seventyone percent of the conversion-to-TKA cases were because of TFOA. We strongly suggest refraining from the use of PFA in knees that show any sign of disease in other compartments than patellofemoral. 
Open Access This article is distributed under the terms of the Creative Commons Attribution 4.0 International License (http:// creativecommons.org/licenses/by/4.0/), which permits unrestricted use, distribution, and reproduction in any medium, provided you give appropriate credit to the original author(s) and the source, provide a link to the Creative Commons license, and indicate if changes were made.

\section{References}

1. Davies AP (2002) The radiologic prevalence of patellofemoral osteoarthritis. Clin Orthop Relat Res 402:206-212

2. McAlindon TE, Snow S, Cooper C, Dieppe PA (1992) Radiographic patterns of osteoarthritis of the knee joint in the community: the importance of the patellofemoral joint. Ann Rheum Dis 51(7):844-849

3. de Winter WE, Feith R, van Loon CJ (2001) The Richards type II patellofemoral arthroplasty: 26 cases followed for 120 years. Acta Orthop Scand 72(5):487-490. doi:10.1080/ 000164701753532826

4. Dy CJ, Franco N, Ma Y, Mazumdar M, McCarthy MM, Gonzalez Della Valle A (2012) Complications after patello-femoral versus total knee replacement in the treatment of isolated patello-femoral osteoarthritis. A meta-analysis. Knee Surg Sports Traumatol Arthrosc 20(11):2174-2190. doi:10.1007/s00167-011-1677-8

5. Insall JN, Dorr LD, Scott RD, Scott WN (1989) Rationale of the Knee Society clinical rating system. Clin Orthop Relat Res 248:13-14

6. van Jonbergen HP, Werkman DM, Barnaart LF, van Kampen A (2010) Long-term outcomes of patellofemoral arthroplasty. J Arthroplasty 25(7):1066-1071. doi:10.1016/j.arth.2009.08.023

7. Cartier P, Sanouiller JL, Khefacha A (2005) Long-term results with the first patellofemoral prosthesis. Clin Orthop Relat Res (436):47-54

8. Hernigou P, Caton J (2014) Design, operative technique and tenyear results of the Hermes patellofemoral arthroplasty. Int Orthop 38(2):437-442. doi:10.1007/s00264-013-2158-0

9. Kooijman HJ, Driessen AP, van Horn JR (2003) Long-term results of patellofemoral arthroplasty. A report of 56 arthroplasties with 17 years of follow-up. J Bone Joint Surg (Br) 85(6):836-840

10. Hernigou P, Flouzat-Lachaniette CH, Delblond W, Duffiet P, Julian D (2013) Computer-assisted navigation in patellofemoral arthroplasty: a new technique to improve rotational position of the trochlea. HSS J Musculoskelet J Hosp Spec Surg 9(2):118-122. doi:10.1007/s11420-013-9328-x

11. Lustig S (2014) Patellofemoral arthroplasty. Orthop Traumatol Surg Res OTSR 100(1 Suppl):S35-S43. doi:10.1016/j.otsr.2013.06.013

12. Merchant AC (2004) Early results with a total patellofemoral joint replacement arthroplasty prosthesis. J Arthroplast 19(7):829-836

13. Zupan A, Snoj Z, Antolic V, Pompe B (2014) Better results with patelloplasty compared to traditional total knee arthroplasty. Int Orthop 38(8):1621-1625. doi:10.1007/s00264-014-2366-2

14. Scheurer P, Reininga IHF, van Jonbergen HPW, van Raay JJAM (2015) Secondary patellar resurfacing following total knee arthroplasty: a cohort study in fifty eight knees with a mean follow-up of thirty one months. Int Orthop 39:1301-1306. doi: 10.1007/s00264-015-2684-Z

15. Walker T, Perkinson B, Mihalko WM (2012) Patellofemoral arthroplasty: the other unicompartmental knee replacement. J Bone Joint Surg Am 94(18):1712-1720. doi:10.2106/ JBJS.L.00539

16. Hart R, Konvicka M, Filan P, deCordeiro J (2008) SPECT scan is a reliable tool for selection of patients undergoing unicompartmental knee arthroplasty. Arch Orthop Trauma Surg 128(7):679-682. doi: 10.1007/s00402-007-0399-3

17. Issa SN, Dunlop D, Chang A, Song J, Prasad PV, Guermazi A, Peterfy C, Cahue S, Marshall M, Kapoor D, Hayes K, Sharma L (2007) Full-limb and knee radiography assessments of varus-valgus alignment and their relationship to osteoarthritis disease features by magnetic resonance imaging. Arthritis Rheum 57(3):398-406. doi: 10.1002/art.22618

18. Kraus VB, McDaniel G, Worrell TW, Feng S, Vail TP, Varju G, Coleman RE (2009) Association of bone scintigraphic abnormalities with knee malalignment and pain. Ann Rheum Dis 68(11): 1673-1679. doi:10.1136/ard.2008.094722

19. Bryant D, Havey TC, Roberts R, Guyatt G (2006) How many patients? How many limbs? Analysis of patients or limbs in the orthopaedic literature: a systematic review. J Bone Joint Surg Am 88(1):41-45. doi:10.2106/JBJS.E.00272

20. Park MS, Kim SJ, Chung CY, Choi IH, Lee SH, Lee KM (2010) Statistical consideration for bilateral cases in orthopaedic research. J Bone Joint Surg Am 92(8):1732-1737. doi:10.2106/JBJS.I.00724

21. Ranstam J (2012) Repeated measurements, bilateral observations and pseudoreplicates, why does it matter? Osteoarthr Cartil 20(6): 473-475. doi:10.1016/j.joca.2012.02.011 